\title{
A influência do Tractatus no critério positivista de significado
}

\section{The Influence of Tractatus in the Positivist Criterion of Meaning}

\author{
Renata Maria Santos Arruda \\ Universidade Federal de Goiás, Brasil \\ renataarrudaprof@gmail.com
}

DOI: https://doi.org/10.22370/rhv2019iss13pp6-17

Recibido: 27/05/2019. Aceptado: 14/08/2019

\section{Resumo}

Uma das motivações para as pesquisas realizadas pelos membros do Círculo de Viena a respeito dos fundamentos da linguagem científica se encontra na obra de Wittgenstein "Tractatus Logico-Philophicus". Embora haja divergências sobre a legitimidade dessa influência, o livro foi, com efeito, tomado como motivação teórica para a estruturação da linguagem científica, desenvolvida pelos empiristas lógicos. Este artigo apresenta as teorias desenvolvidas pelos membros do Círculo de Viena ressaltando os elementos presentes no Tractatus que foram tomados, em grande parte, como influência sobre o "critério de significado" de uma proposição filosófica adotado pelos empiristas lógicos na tentativa de se estabelecer uma fundamentação para o conhecimento.

Palavras-chave: Círculo de Viena, Wittgenstein, estrutura lógica, correspondência, verificacionismo.

\begin{abstract}
One of the motivations for the researches leaded by the members of Vienna Circle with regard to the foundations of scientific language is found on Wittgenstein's "Tractatus Logico-Philophicus". Even though there are divergences about the legitimacy of this influence, the book was, in effect, taken as a theoretical motivation for the structuring of scientific language, developed by logical empiricists. This paper will present the theories developed
\end{abstract}


A influência do Tractatus no critério positivista de significado

Renata Maria Santos Arruda

by members of Vienna Circle emphasizing the elements presents in Tractatus that were taken, largely, as influence over the "criterion of meaning" of a philosophical proposition adopted by logical empiricists in an attempt to set a foundation for knowledge.

Keywords: Vienna Circle, Wittgenstein, logical structure, correspondence, verificationism.

\section{Introdução}

Há exatos 90 anos, em agosto de 1929, o movimento filosófico engendrado pelo Círculo de Viena demarcava suas perspectivas filosóficas por meio da publicação de seu "Manifesto", marcando a consolidação de uma nova abordagem da ciência na história da Filosofia. Meu objetivo nesse artigo é celebrar esse momento histórico pelo resgate de alguns elementos desse movimento relacionados aos seus posicionamentos teóricos iniciais; mais especificamente, a controversa influência de algumas ideias do Tractatus na forma em que os pensadores do Círculo viam a relação entre a realidade e a linguagem.

Com a nomeação do físico Moritz Schlick para ocupar a cadeira de Filosofia e de História das Ciências Indutivas na Universidade de Viena, em 1929, formou-se um grupo que, frente aos avanços tecnológicos e científicos da época, propôs-se a discutir os rumos da ciência e o papel da filosofia nesse novo contexto. Entre os simpatizantes desse movimento estavam A. J. Ayer, Carl G. Hempel, Hans Reichenbach, entre outros, sendo que seus membros principais eram Kurt Gödel, Hans Hahn, Otto Neurath, Viktor Kraft e Rudolf Carnap. Enquanto corrente filosófica, a orientação teórica daqueles pensadores foi caracterizada como Neopositivismo ou Positivismo Lógico. Essa corrente tinha como objetivo não só aproximar ciência e filosofia por meio do empirismo e separar esta da metafísica, mas também renovar os problemas filosóficos por meio do aspecto formal do conhecimento (Hahn et al.1986, 9). Sob esse título, as pesquisas dos seus membros buscavam uma interpretação do conhecimento em termos lingüísticos; a investigação empírica, que atribui validade ao conhecimento resultado das experiências, do contato com o mundo externo, seria pautada por um critério lógico que determinaria a validade do conhecimento adquirido nesse tipo de investigação.

Por meio da estruturação da linguagem lógica e do reducionismo aos termos observacionais, que se conectam mais diretamente à experiência por referência direta aos objetos físicos, os pensadores do movimento positivista também se mobilizaram na tentativa de unificação da linguagem da ciência em uma linguagem lógica, científica, objetiva, em detrimento de uma linguagem natural, onde seriam possíveis significações subjetivas. Com um vocabulário definido universalmente seria possível que os termos de toda a ciência se referissem a um significado determinado, onde os dados empíricos unificassem diferentes teorias, permitindo o intercâmbio inequívoco de idéias entre os pesquisadores sobre uma base empírica comum, o que viria a contribuir para o progresso e desenvolvimento da ciência (Hahn et al. 1986, 12). Com o intuito de estabelecer uma unificação da linguagem 
A influência do Tractatus no critério positivista de significado

Renata Maria Santos Arruda

da ciência, os filósofos do positivismo lógico procuraram estruturar uma linguagem com base em certos conceitos desenvolvidos no Tractatus de Wittgenstein, como veremos a seguir.

\section{As teses do Tractatus relevantes para o positivismo lógico}

Toda a análise acerca da estrutura lógica no Tractatus é desenvolvida por meio do traço fundamental da filosofia, que consiste, para Wittgenstein, na propriedade da elucidação de conceitos, de clarificação de idéias. A filosofia permite lançar luz sobre as relações implícitas nas proposições da linguagem e, nesse sentido, revela a natureza e o sentido dessas proposições. Enquanto expõe a estrutura lógica, a filosofia delimita a expressão do pensamento e da linguagem e revela, conseqüentemente, os limites do pensamento e as possibilidades da linguagem.

Um dos pressupostos das ideias desenvolvidas no Tractatus acerca da linguagem é que o sentido das proposições compostas é compreendido "de baixo para cima", o que exige que se deva conhecer inicialmente o significado das palavras. Esse processo se inicia com a compreensão do significado das palavras, que determinam o significado das proposições elementares. Por outro lado, devem-se pressupor também certas regras de ligação entre essas palavras, regras que estabeleçam os sentidos das diferentes frases através da gramática de uma determinada língua. O caráter do composicionalismo do Tractatus é descrito com bastante clareza no aforismo 4.024: "Entende-se uma proposição caso se entendam suas partes constituintes". Em outros termos, Wittgenstein indagaria: como entender o significado de uma proposição nunca antes ouvida senão pela compreensão do significado de suas palavras? Sua semântica composicionalista responde de maneira adequada à essa questão, e demonstra que com as mesmas palavras e expressões novos sentidos podem ser comunicados. Dessa forma, as palavras formam uma espécie de quebra-cabeça, e as regras gramaticais estabelecem determinados encaixes que permitem diferentes tipos de peças, as quais podem ser permutadas para oferecerem diferentes aspectos acerca do todo.

A conexão dessa estrutura da linguagem com a realidade é discutida no Tractatus pela compreensão de que a linguagem reflete, em um sentido imagético, estrutural, a ordem do mundo, à medida que a linguagem fale sobre a ocorrência ou não na realidade do fato ou do estado de coisas que ela expressa. Mas a verdade de uma sentença pode também ser tautológica, analítica, verdadeira apenas em virtude da sua forma lógica, e, assim, não diz nada sobre o mundo. Quando se trata de um fato expresso na linguagem, o modo como os elementos dos estados de coisas estão uns para os outros é representado pelas proposições elementares, que, conseqüentemente, são formadas pelos nomes simples, os quais representam objetos simples. Logo, pela associação das proposições elementares em uma função de verdade, o valor de verdade de uma proposição complexa depende, em última análise, de que a denominação dos objetos pelos nomes simples seja a adequada, isto é, que aquilo que os nomes simples nomeiam represente os próprios objetos a que eles se referem. 
A influência do Tractatus no critério positivista de significado

Renata Maria Santos Arruda

A análise lógica de uma proposição complexa revela a sua formação a partir de proposições elementares, e cada uma dessas proposições afigura um estado de coisas. A combinação possível - lógica - desses estados de coisas é representada pelas proposições complexas. Em outras palavras, a verdade de uma proposição complexa depende da operação de verdade das proposições elementares na medida em que estas representem um estado de coisas existente, isto é, na medida em que forem um fato. Assim, a função de verdade formada pela combinação das proposições elementares para a definição da verdade da proposição complexa, permite, enfim, afigurar a disposição dos objetos do mundo, como eles estão uns para os outros, na proposição complexa.

Wittgenstein traça um paralelo entre a linguagem e o mundo, onde a linguagem reflete a estrutura lógica do mundo, compondo sua forma da realidade. $\mathrm{Na}$ forma da realidade, a relação entre os objetos da realidade é comparada à relação entre os objetos da afiguração: os elementos da figuração devem estar relacionados como estão as coisas no mundo. A forma de afiguração, que é a forma lógica comum à figuração e ao afigurado, ao possibilitar as inter-relações entre os elementos afigurados, ou seja, a combinação de elementos lingüísticos representando um estado de coisas possível pode realizar uma descrição verossímil feita pela linguagem acerca do mundo. Nessa perspectiva, revela-se o aspecto correspondencionalista do Tractatus através da representação do mundo por meio da linguagem. É importante ressaltar que a estrutura lógica é representada não como um objeto do mundo, mas como uma relação existente entre os objetos afigurados. Pois se a forma lógica pudesse ser representada, seria equivalente aos elementos afiguráveis, e a cada representação lógica dos elementos afiguráveis decorrer-se-ia outra representação que, por sua vez, seria formalizada por uma outra representação, e assim por diante, configurando-se um regresso ao infinito. Ou seja, a forma lógica, que é comum à linguagem e à realidade, não pode ser afigurada, ela é mostrada nas relações entre os objetos e as proposições.

Desse modo, a análise filosófica realizada no Tractatus expõe a forma do pensamento, da linguagem e do mundo, e mostra como eles são permeados por uma única estrutura lógica, sua forma de afiguração. Não podem existir, de acordo com o que é defendido no Tractatus, diferentes formas de se pensar logicamente. A lógica existente nas relações entre os objetos, nos estados de coisas, no pensamento e na linguagem, é uma só. Não existem, portanto, diferentes formas de se pensar o mundo com sentido, isto é, não existe uma maneira ilógica de se pensar com sentido.

Além das proposições com sentido, os outros tipos de sentenças que podem existir são os contrassensos, tautologias, contradições e os enunciados da matemática. Nos contrassensos, ocorre uma combinação de nomes logicamente incompatíveis, formando uma pseudoproposição e ultrapassando os limites da razão, pois, apesar de respeitarem as regras gramaticais para a construção de uma sentença inteligível, estes enunciados não afiguram um estado de coisas, não falam nada sobre o mundo. A combinação que ocorre nesse tipo de enunciado não é autorizada pelos fatos, não possui correlato ontológico, enfim, não é dada pela possibilidade de fatos no mundo. Por outro lado, as proposições sem 
A influência do Tractatus no critério positivista de significado

Renata Maria Santos Arruda

sentido, que dizem respeito às tautologias, contradições e aos enunciados da matemática, e não representam um estado de coisas em absoluto. Um estado de coisas é representado por uma proposição elementar; a proposição elementar diz algo sobre o mundo: descreve o que as coisas são e como elas estão, isto é, tem um sentido que deve poder ser verdadeiro ou falso, e as tautologias ou contradições dizem respeito ao que é necessariamente verdadeiro e necessariamente falso, respectivamente. As proposições sem sentido, portanto, não descrevem nenhum estado de coisas.

Algumas teses de Wittgenstein, presentes no Tractatus, tais como a teoria da figuração e certas noções sobre a tabela de verdade, foram aceitas em um primeiro momento nas pesquisas do Círculo de Viena ${ }^{1}$. É importante notar que Wittgenstein não participava das reuniões do Círculo de Viena e não compartilhava diretamente das teses desenvolvidas por seus membros, que, apesar disso, consideravam as teorias do Tractatus como precursoras do positivismo lógico, ganhando uma posição de destaque para a fundamentação, de um modo específico, do "critério de significado". Mesmo permanecendo distante das teorias influenciadas por ele, os seguintes livros da fase "verificacionista" de Wittgenstein foram o resultado de discussões com alguns membros mais influentes do Círculo de Viena, onde o filósofo participa esclarecendo conceitos e algumas questões referentes ao Tractatus: do diálogo com Schlick e Waismann, publicou-se postumamente "The Principles of Linguistic Philosophy"2 (1965) e "Ludwig e em 1967 Wittgenstein und der Wiener Kreis" (1996), sendo que este consiste em anotações feitas por Waismann dos comentários de Wittgenstein; das anotações de G. E. Moore publicou-se em 1964, posteriormente ao Tractatus, "Philosophische Bemerkungen"” (Moore apud Barbosa Filho 1981, 21).

\section{O critério positivista de significado}

Na medida em que descrevia a estruturação do pensamento, do mundo e da linguagem, as teses do Tractatus forneciam elementos para a constituição de certas teorias dos Positivistas Lógicos (Barbosa Filho 1981, 22). Estes tomavam como ponto de partida a pesquisa empírica, onde desenvolviam teorias correspondencionalistas sobre o conhecimento, justificando a verdade como correspondência à realidade empírica e assumindo um compromisso lógico com a coerência dos sistemas teóricos (Hempel 1935, 49). O discurso acerca do conhecimento deveria estar fundamento nessas duas bases, pois estaria

\footnotetext{
${ }^{1}$ Encontra-se também em textos posteriores ao Tractatus o desenvolvimento da noção de verificabilidade, na chamada fase verificacionista (Monk 1995, 21) ou fenomenalista (Barbosa Filho 1981, 21) de Wittgenstein.

${ }^{2}$ Segundo Monk $(1995,260)$, o livro em questão serviria como uma introdução às idéias do Tractatus, e fora composto por notas tomadas por Waissman e Schlick em reuniões com Wittgenstein, onde este discutia a respeito do Tractatus. O livro não foi publicado àquela época, pois Wittgenstein se negou, posteriormente, a colaborar com os positivistas.

${ }^{3}$ De acordo com Barbosa Filho $(1981,21)$, as anotações de Moore que deram origem ao livro supracitado se referem às aulas proferidas por Wittgenstein entre 1930 e 1933. Em Barbosa Filho (ibíd., 31) estão relacionados outros nove importantes livros de Wittgenstein que dizem respeito à temática do Círculo de Viena.
} 
A influência do Tractatus no critério positivista de significado

Renata Maria Santos Arruda

comprometido com o mundo e com o pensamento, e, assim sendo, a sua plausibilidade estaria garantida de modo completo pelos meios considerados indicadores da verdade: a experiência e a lógica.

O empirismo lógico, na sua busca por uma interpretação do conhecimento em termos lingüísticos, tentou estabelecer uma fundamentação para o conhecimento acerca do mundo em uma base empírica, admitida como o princípio lógico ou temporal da construção dos saberes humanos ${ }^{4}$, sistematizada por uma linguagem adequada (Schlick 1988a, 66). O conhecimento legítimo seria, nesses termos, representado pela ciência natural, e a linguagem que ordenaria os conceitos científicos transformava-se numa metodologia embasada por conceitos da lógica. A ciência da época apresentava grandes avanços: a Geometria e as teorias da Física, a partir do desenvolvimento das geometrias não-euclidianas e da teoria da relatividade, perdiam o terreno do absoluto antes construído por uma única forma de descrição dos fenômenos físicos e geométricos (Hahn et al. 1986, 15). A matemática se renovara com as idéias desenvolvidas no Tractatus, a partir das contribuições de Frege e Russell para a matemática, na tentativa de atribuir a esta uma base lógica (Kenny 1995, 46). Nesse contexto, as considerações dos positivistas lógicos acerca da fundamentação do conhecimento acompanhavam as transformações pelas quais passava o conhecimento científico, prático e teórico. O pensamento da época se transformava com a busca de um conhecimento sólido, onde se pudesse, mesmo que em princípio, vislumbrar respostas definitivas para as questões que sempre motivaram as investigações sobre o mundo que nos cerca. Diferentemente da metafísica, a que os Positivistas atribuíam o empreendimento de especulações inesgotáveis sobre problemas insolúveis e conceitos que transcendem a experiência, os membros do Círculo de Viena, ao se debruçarem sobre o mundo físico através da ciência, tinham a pretensão de traduzir, por meio da Filosofia, algumas certezas que o mundo pudesse oferecer (Hahn et al. 1986, 10).

A influência do Tractatus sobre o "critério de significado" de uma proposição, adotado pelos positivistas lógicos, parte de uma interpretação epistemológica dos conceitos de função de verdade e figuração presentes nesse livro (Barbosa Filho 1981, 22). Wittgenstein não estava interessado em definir ou em apontar para qualquer objeto do mundo físico e denominá-los a partir dos conceitos da sua teoria. Sua preocupação era puramente lógica, formal. O que está pressuposto no Tractatus é a existência dos objetos para uma afiguração completa do mundo, tratando-se apenas das relações lógicas desses objetos, isto é, da forma lógica como são constituídos e do sentido da proposição complexa a partir do valor de verdade das suas proposições elementares. O positivismo lógico se encarregou, a partir da estrutura lógica da linguagem sistematizada pelo Tractatus, de acrescentar um conteúdo empírico às proposições lógicas. Esse conteúdo seria constituído por objetos do mundo físico, os quais seriam nomeados pelos nomes simples e descritos pelas proposições elementares e complexas.

${ }^{4}$ Esta opinião é expressa de um modo geral pelos positivistas lógicos, apesar de não acordarem se o princípio seria temporal ou lógico. A formulação aceita por Schlick, por exemplo, é que o princípio do conhecimento possa ser, simultaneamente, temporal e lógico. 
A influência do Tractatus no critério positivista de significado

Renata Maria Santos Arruda

O critério que determina o significado de um enunciado, adotado pelos positivistas lógicos, pode ser resumido na seguinte afirmação de Schlick:

Enunciar o sentido de uma frase equivale a estabelecer as normas segundo as quais a frase deve ser empregada, o que significa enunciar a maneira pela qual se pode constatar a sua verdade (ou a sua falsidade). O significado de uma proposição constitui o método da sua verificação. (Schlick 1988b, 85)

O critério de significado dos positivistas está baseado na idéia do Tractatus que diz respeito à função de verdade de uma proposição complexa em relação a uma proposição elementar (Wittgenstein 2001, 63). Dessa forma, as proposições elementares só se tornam verdadeiras, e, conseqüentemente tornam as proposições complexas verdadeiras, se os nomes simples estiverem substituindo, na proposição, os objetos que se propõem a afigu$\operatorname{rar}^{5}$. Os nomes simples, por sua vez, estariam em conexão direta com a realidade, seriam fixados por relação direta com o mundo. Assim sugere o Tractatus no aforismo 4.21: "A proposição mais simples, a proposição elementar, assere a existência de um estado de coisas"; em 4.22: "A proposição elementar consiste em nomes. É uma vinculação, um encadeamento de nomes", e em 3.22: "O nome substitui, na proposição, o objeto". Portanto, caso se reduzisse o sentido de uma proposição complexa ao significado dos seus termos componentes, uma proposição com sentido só poderia ser aquela que estivesse dada na realidade.

Pressupondo uma estrutura lógica na qual os elementos do mundo material pudessem ser inseridos, a teoria dos positivistas implicaria, desse modo, a definição de um significado a partir de uma linguagem e de regras lógicas, metodologicamente estabelecidas, que permitiriam definir a validade dos raciocínios desenvolvidos, associados a um conteúdo empírico necessariamente vinculado às proposições. Assim, a fundamentação do conhecimento dependeria do critério de significado para o desenvolvimento de seus conceitos basilares, pois, de posse do significado dos termos pertinentes a uma teoria, poder-se-ia descrever adequadamente as relações dos objetos no mundo e a verificação dos enunciados científicos.

A análise lógica e sua aplicabilidade ao material empírico tornaram possível aos positivistas lógicos, por meio da elucidação dos termos componentes de uma proposição complexa, estruturarem o reducionismo de conceitos superiores mais complexos a conceitos inferiores mais básicos, mais próximos da experiência (Hahn et al. 1986, 12). Esta estruturação formaria um sistema de constituição dos conceitos, que os ordenaria de acordo com a referência destes aos objetos físicos, o que tornaria a ciência unificada. A filosofia, no contexto teórico do positivismo lógico, tornou-se mais do que nunca filosofia da ciência, cabendo a ela a tarefa de elucidar as proposições científicas que se referem diretamente ou indiretamente à experiência e estabelecer o método logicamente adequado para

${ }^{5}$ De acordo com Barbosa Filho (1981,21), Wittgenstein estabeleceu, nas "Philosophische Bemerkungen", o seu próprio critério de significado, relacionando as proposições elementares com as proposições fenomenais. 
A influência do Tractatus no critério positivista de significado

Renata Maria Santos Arruda

a verificação dos enunciados científicos, restando à ciência verificar aqueles enunciados (Hahn et al. 1986, 18). Através de uma linguagem unificada entre ciência e filosofia, pretendia-se chegar também a uma explicação unitária do mundo (Hahn et al. 1986, 10). Portanto, a assim chamada "concepção científica do mundo" do Círculo de Viena buscou desenvolver-se a partir da clareza e rigor de conceitos, exatidão na linguagem e no simbolismo lógico, independentemente da origem e da orientação científica.

A linguagem, aplicada ao material empírico, se estabelecia, dessa forma, como uma metodologia para a clarificação dos conceitos da ciência, e os membros do Círculo de Viena reconheciam como legítima a tarefa da filosofia, descrita no Tractatus, como "atividade" de elucidação do conhecimento. Esta proposta é amplamente divulgada no "manifesto" escrito por membros do Círculo de Viena, mas especialmente no seguinte trecho:

A concepção científica do mundo desconhece enigmas insolúveis. O esclarecimento dos problemas filosóficos tradicionais conduz a que eles sejam parcialmente desmascarados como pseudoproblemas e parcialmente transformados em problemas empíricos sendo assim submetidos ao juízo das ciências empíricas. A tarefa do trabalho filosófico consiste neste esclarecimento de problemas e enunciados, não, porém, em propor enunciados "filosóficos" próprios. (Hahn et al. 1986, 10)

Ao repudiarem a metafísica em virtude da ausência de referencial empírico de seus termos, os positivistas lógicos também foram considerados "anti-filósofos" por se voltarem exclusivamente para as questões pertinentes ao campo que antes cabia exclusivamente à ciência, utilizando a lógica como ferramenta de elucidação (Neurath 2003, 121). Os positivistas acreditavam que de um conjunto de enunciados mal formulados e equivocadamente interpretados poderia se chegar a problemas inexistentes, decorrentes apenas dos erros lógicos da má constituição desses enunciados, que resultariam na má compreensão dos mesmos. A lógica, como instrumento de análise, dissecaria a linguagem em sua estrutura e em suas conexões com os nomes simples, os quais, finalmente mediariam as proposições com a realidade e evitariam os danos de uma descrição equivocada da realidade.

Vinculada à ciência, a Filosofia desenvolvida pelos Positivistas Lógicos a partir da leitura que fizeram do Tractatus, tinha como função fundamental analisar as proposições científicas até os seus termos últimos, identificar os seus objetos e, finalmente, apresentar o sentido dessas proposições, vinculando-as à experiência. O Tractatus, ao sistematizar a linguagem e ao conectá-la ao mundo, delineou a estrutura pela qual os positivistas instituiriam convencionalmente os objetos pertencentes à base empírica nas diferentes teorias desenvolvidas por eles, entre elas o fisicalismo e o fenomenalismo. Sob essa perspectiva, qualquer raciocínio só poderia ser intitulado de "filosófico" se seus elementos se remetessem à experiência.

Consequentemente, o princípio verificacionista também se tornou um critério de demarcação entre ciência e não-ciência. Por reduzir qualquer enunciado significativo a um enunciado observacional, os enunciados que não referissem a um conteúdo empírico se- 
A influência do Tractatus no critério positivista de significado

Renata Maria Santos Arruda

riam identificados como isentos de significado. Seriam assim considerados, da mesma forma que Wittgenstein define no Tractatus, pseudoproposições ou contra-sensos. Portanto, no contexto do positivismo lógico, assim como no Tractatus, só poderiam haver dois tipos de enunciados aceitos no corpo da ciência: as proposições tautológicas (as expressões matemáticas ou da lógica), pois essas dizem respeito às leis do pensamento, e as proposições empíricas, que seriam proposições com sentido (Hahn et al. 1986, 10).

É importante destacar que o significado de um enunciado qualquer está subsumido a determinadas regras lingüísticas, previamente estabelecidas; regras que visem definir a referência dos termos e o sentido das proposições. Somente de posse de um significado definido semanticamente e sintaticamente, podemos atribuir às proposições, em seguida, um valor de verdade. Que um enunciado possua um significado não se quer dizer que ele seja verdadeiro, mas sim que se têm as condições necessárias para afirmá-lo verdadeiro ou falso. E essa afirmação, na presente abordagem, constitui na verificação do fato ou estado de coisas expressos por esse enunciado.

O método de verificação dos enunciados da ciência sofreu importantes alterações ao longo do desenvolvimento das idéias propostas pelos positivistas lógicos, e a mudança mais significativa foi o estabelecimento de um convencionalismo para a base empírica. Com isso, os elementos últimos de qualquer enunciado seriam definidos a partir das condições e necessidades de contato com a realidade da teoria à qual o enunciado estivesse subsumido (Hempel 1935, 58). Nesse sentido, não haveria mais um único "critério de significado" e nem mesmo um consenso acerca da possibilidade de uma unificação da ciência por meio de uma única base empírica, porém, não se alteraria a necessidade de se estabelecer os elementos fundamentais para uma compreensão geral de um corpo de enunciados relativos a uma teoria.

\section{Conclusão}

A teoria do conhecimento desenvolvida pelos membros do Círculo de Viena a partir de suas leituras do Tractatus, que os unia em torno de um critério de significado, baseava-se na estipulação de uma interpretação das proposições filosóficas, e em um método para a verificação dessas proposições. Não é casual, portanto, a escolha dos termos "empirismo lógico" pelos membros do Círculo de Viena para definir seu posicionamento epistemológico, fazendo referência à aplicação da ferramenta lógica ao empirismo em seu sentido moderno, o qual encontrava na experiência sensível a origem das nossas ideias e do nosso conhecimento. A lógica se tornaria então uma linguagem específica que estruturaria e articularia os dados dos sentidos. Por meio da análise lógica pretendia-se definir a verificabilidade das proposições, revelando as condições nas quais as proposições poderiam ser testadas empiricamente pelas ciências. A filosofia passaria a ser uma ferramenta para a elucidação do pensamento, dos conceitos; a análise lógica revelaria o sentido do enunciado, mostrando o que ele realmente quer dizer, e seu significado estaria relacionado à possibilidade de verificá-lo na experiência. Estes aspectos são retratados, na linguagem 
A influência do Tractatus no critério positivista de significado

Renata Maria Santos Arruda

do Tractatus, como uma teoria da figuração, onde a linguagem corresponde aos fatos da realidade, e ambas, linguagem e realidade, se afiguram uma à outra, desde suas partes atômicas até as mais complexas, e o critério de significado dos positivistas pretendia aplicar essa correspondência no âmbito dos enunciados científicos. Em virtude da preocupação de que a linguagem empregada na filosofia deva refletir a realidade, a metafísica, entendida como parte da filosofia que investiga as essências das coisas para além do dado concreto, é criticada pelos empiristas lógicos exatamente por não se referir à experiência empírica, ao mesmo tempo em que, por exemplo, usa termos abstratos como indicando entidades concretas.

Curiosamente, a própria concepção do método de verificação engendrava a mudança pela qual passaria o critério de significado. Por um lado, membros do Círculo como Carnap e Neurath passaram a defender que enunciados são construções linguísticas que, como tais, só podem ser avaliados por parâmetros também linguísticos (Hempel 1935, 50). Enunciados e fatos são entidades distintas, e isso implicaria em que podemos avaliar a compatibilidade entre enunciados e analisar sua relação por meio de regras que produzam certas inferências, isto é, outros enunciados, a partir deles. Carnap passou a manter as ideias de Wittgenstein apenas a respeito da combinação entre enunciados para a formação de enunciados moleculares e da comparação entre eles sem se recorrer à realidade, já que os enunciados imediatos - seus enunciados "protocolares" - sobre a realidade deveriam ser aceitos imediatamente como verdadeiros (Hempel 1935, 51). Em suma, manteve-se a relação linguística entre enunciados, mas abandonou-se a estrita necessidade de correspondência com a realidade, também defendida no Tractatus.

De outra parte, e como consequência da aceitação dos limites que ligam a linguagem à realidade, os membros do Círculo reconheceram que o princípio verificacionista excluía, contraditoriamente à prática científica, todas as leis gerais do grupo de enunciados significativos, pois um enunciado de caráter geral não poderia ser verificado em sua totalidade. De acordo com a posição do Tractatus adotada pelo Círculo, um enunciado é verdadeiro quando retrata um estado de coisas existente na realidade, e dado o caráter universal e atemporal de uma lei empírica, entendida como uma afirmação molecular, seria impossível a verificação, em sua totalidade, de todos os enunciados atômicos que a compõe.

Com o convencionalismo adotado no final da fase verificacionista do Círculo de Viena, a linguagem da ciência poderia ainda manter os mesmos critérios lógicos para a determinação da validade de seus enunciados, mas a correspondência estrita com a realidade e a aceitação de uma única base empírica deixaria de representar o elo comum a todo o conhecimento. Afirmar a busca por um fundamento inabalável sobre o qual ancorar a teoria na realidade seria uma suposição muito forte, que estaria baseada na ideia de que existem propriedades absolutamente definidas às quais se poderiam referir inequivocamente. Carnap, por exemplo, reconhece que os próprios enunciados de experiência imediata devam ser revisados em determinados contextos em detrimento de outros enunciados que se mostrem mais bem fundamentados (Hempel 1935, 53). Desse modo, o valor de verdade 


\section{A influência do Tractatus no critério positivista de significado}

Renata Maria Santos Arruda

de uma proposição passaria a ser resultado não somente da correspondência com os fatos pertinentes a um determinado sistema teórico, mas dependeria, em algumas interpretações, quase que exclusivamente da coerência entre as proposições desse sistema.

Diante da abdicação progressiva da ideia de que a realidade é sempre acessada inequivocamente pela linguagem, a comunidade científica passar a desempenhar um papel fundamental no processo de validação dos enunciados empíricos. Isso leva à busca para se garantir, de maneira criteriosa, a confiança no conhecimento sobre a realidade. Para Carnap (Hempel 1935, 57-58), o desenvolvimento da ciência se deve ao acordo dos cientistas em torno da verdade de seus enunciados, à validação de sua adoção via experiência, e à consequente formulação de outros enunciados com base naqueles. A produção de enunciados verdadeiros é fruto de um treinamento que capacita os cientistas a elaborarem esses enunciados de uma maneira específica, mais precisa e adequada ao corpo da ciência. Ainda que diferentes sujeitos possam produzir diferentes enunciados, a comunidade que trabalha com a ciência deve se colocar em acordo sobre quais enunciados devem ser adotados em prol de outros enunciados e das teorias que se julguem mais relevantes.

Finalmente, o recorte que os empiristas lógicos fizeram do Tractatus no posicionamento inicial em torno do projeto de reestruturação da epistemologia impulsionou uma soma de esforços para renovação da filosofia e da lógica a partir da análise da linguagem. Uma das lições finais desse processo de "reconstrução" do conhecimento a respeito da ciência foi o de reconhecer que, ao mesmo tempo em que o mundo empírico não pode equivaler absolutamente a elementos linguísticos, enunciados também têm sentido para além do que se pode determinar empiricamente. Mesmo que Wittgenstein objetivasse outra direção para o Tractatus diferente daquela empreitada pelo Círculo de Viena, o contexto da época e a aproximação entre seus pensadores e suas idéias levaram a cabo, naquele momento, a tarefa que se incumbiram de realizar: a de buscar uma fundamentação do conhecimento.

\section{Referências Bibliográficas}

Barbosa Filho, B. (1981). Sobre o positivismo de Wittgenstein. Manuscrito, 5(1): 17-32.

Hahn, H., Neurath, O., Carnap, R. (1986). A Concepção Científica do Mundo "O Círculo de Viena". Cadernos de História e Filosofia da Ciência, vol.10, https://www. cle.unicamp.br/eprints/index.php/cadernos/article/download/1220/1011. Consulta: 26/05/2019.

Hempel, Carl. (1935). On the Logical Positivists' Theory of Truth. Analysis, 2(4), https://www.jstor.org/stable/3326781?seq=1\#page_scan_tab_contents. Consulta: 26/05/2019.

Kenny, A. (1995). Wittgenstein. Madrid: Alianza Editorial.

Monk, Ray. (1995). Wittgenstein: o dever do gênio. São Paulo: Companhia das Letras. 


\section{A influência do Tractatus no critério positivista de significado \\ Renata Maria Santos Arruda}

Neurath, O. (2003). Fisicismo: A Filosofia no Círculo de Viena. Philosophos 8(1), https:// revistas.ufg.br/philosophos/article/download/3209/3193/. Consulta: 26/05/2019.

Schlick, M. (1988a). O Fundamento do Conhecimento. In P. R. Mariconda (org.), Coletânea de Textos Moritz Schlick, Rudolf Carnap, pp. 65-81. São Paulo: Nova Cultural.

Schlick, M. (1988b). Sentido e verificação. In P. R. Mariconda (org.), Coletânea de Textos Moritz Schlick, Rudolf Carnap, p. 84. São Paulo: Nova Cultural.

Waismann, F. (1965). The Principles of Linguistic Philosophy. London: Macmillan.

Waismann, F. (1996). Ludwig Wittgenstein und der Wiener Kreis: Gespräche. Berlin: Suhrkamp Verlag.

Wittgenstein, L. (2001). Tractatus Logico-Philosophicus. São Paulo: Editora da Universidade de São Paulo. 